\title{
Impact of Nationwide Lockdown on Students of Higher Education
}

\author{
${ }^{1}$ Jasbir Singh, ${ }^{2}$ Rahul Kundal, ${ }^{3}$ Neharica Subhash \\ ${ }^{1}$ Director, CSSEIP, University of Jammu, India \\ ${ }^{2}$ Professional Assistant, CSSEIP, University of Jammu, India \\ ${ }^{3}$ Research Assistant, CSSEIP, University of Jammu, India

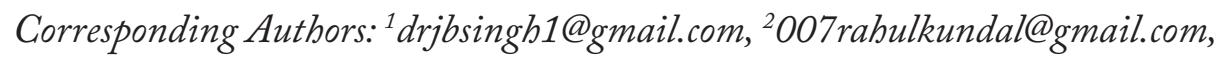 \\ 3"nebarica203@gmail.com
}

\begin{abstract}
Following the onset of the COVID-19 pandemic in India, the Union Government of India announced nationwide lockdown. As the nationwide lockdown was implemented in India from $25^{\text {th }}$ of March 2020, almost every sector of the Indian economy came to a halt. Along these circumstances, all kinds of educational institutions were also shut down. Evidently, and as anticipated, the students were among those groups that suffered the most during nationwide lockdown. Consequently, learning status of the students was hard-hit. The present study is an attempt to measure the impact of nationwide lockdown on the learning status of the students who were pursuing undergraduate and postgraduate courses at the University of Jammu at the time of announcement of nationwide lockdown. In order to collect data for the present study, an online questionnaire was developed using the Google Forms platform and link of the questionnaire was provided to 300 students who were pursuing undergraduate and postgraduate courses at the University of Jammu at that time. The responses from the students were received between $20^{\text {th }}$ of August 2020 and $26^{\text {th }}$ of August 2020. The data were then tabulated and analysed. It was observed that a large proportion of the respondents could only complete half of their syllabus (or even less) through online learning mode during nationwide lockdown, and that they had to face a variety of problems, such as anxiety, poor physical heath, poor internet connectivity, etc. It is suggested that the governments and the concerned authorities must aim to make policies to establish a resilient educational structure
\end{abstract}


that is able to tackle situations like the COVID-19 pandemic and nationwide lockdown, so that the young mind' productivity is not compromised.

Keywords: COVID-19, Indian economy, educational institutions, undergraduate, postgraduate, University of Jammu.

\section{Introduction}

Alvi and Gupta (2020) explain that most of the relief and rehabilitation packages that were announced by the governments in India following the onset of 'COVID-19 pandemic' induced nationwide lockdown aimed at economic rehabilitation. ${ }^{1}$ Even though the Union Government of India announced 250 billion dollar package in order to provide stimulus to the Indian economy and its sub-sector, the education sector was ignored, despite the fact that this sector plays an important role in generating and enhancing the human resource and social capital of India. Nationwide lockdown left harmful implications on the education sector, which ultimately affected educational outcomes, mostly of the urban and the rural poor.

As far as the estimates of the UNESCO (2020) are concerned, more than 0.3 billion school going students had to bear the ill effects, regarding their education, due to closures of schools as a consequence of nationwide lockdown. ${ }^{2}$ Estimates suggested that the dropout rates were likely to be depressing due to situations like nationwide lockdown and these will turn out to be more severe in the case of female students, as female children are, mostly, avoided when it comes to familial decisions regarding allocation and distribution of resources. ${ }^{3}$

Alvi and Gupta (2020) have talked about online mode of learning, and they further elaborate that some crucial steps had been undertaken by a number of educational institutions to guarantee continuation of teaching curriculum and other related activities by switching to online modes of lecturing and teaching. ${ }^{4}$

1 Muzna Alvi and Manavi Gupta, "Learning in Times of Lockdown: How Covid-19 Is Affecting Education and Food Security in India," Food Security 12, no. 4 (2020): 793-96, https://doi.org/10.1007/s12571-02001065-4.

2 UNESCO. (2020). School closures caused by Coronavirus (COVID-19). Retrieved August 3, 2020, from https://en.unesco.org/covid19/educationresponse.

3 Ravi Prakash et al., "Correlates of School Dropout and Absenteeism among Adolescent Girls from Marginalized Community in North Karnataka, South India," Journal of Adolescence 61 (2017): 64-76.

4 Alvi and Gupta, "Learning in Times of Lockdown: How Covid-19 Is Affecting Education and Food Security in India." 
Jena (2020) reviewed that the overall education sector in India had been affected due to nationwide lockdown. ${ }^{5} \mathrm{He}$ further elaborated the instability that had emerged in the higher education sector in India, and opined and suggested that 'COVID-19 pandemic' induced nationwide lockdown presented with an opportunity to bring changes in pedagogical approaches. Raj (2020) talked about COVID-19 pandemic and nationwide lockdown that led to temporary shutdown of educational institutions pan-India. ${ }^{6} \mathrm{He}$ observed a huge gap that existed due to lack of proper infrastructure that would support e-learning and virtual mode of education. He registered that the education sector in India had been among the largest in the world, comprising a large network of about 1.4 million schools, near about a 1000 universities, about 40000 colleges, and approximately 11000 Stand Alone Institutions that were listed by the All India Survey on Higher Education (AISHE).

\section{Methodology}

Literature concerning the 'COVID-19 pandemic' induced nationwide lockdown was surveyed and upon the basis of the survey of literature, an online questionnaire was developed using the Google Forms platform. The link to this online questionnaire was provided to 300 students (150 students each from undergraduate courses and postgraduate courses) of the University of Jammu. The responses from the respondents were received between $20^{\text {th }}$ of August 2020 and $26^{\text {th }}$ of August 2020. The data were then tabulated and represented using the simple percentage method.

\section{General Details of the Respondents}

Distribution of the respondents as per level of education they were attending is exhibited in table 1 . Out of the total respondents, 50 percent $(n=150)$ were attending undergraduate courses and 50 percent $(n=150)$ were attending postgraduate courses at the University of Jammu.

5 Pravat Kumar Jena, "Impact of Covid-19 on Higher Education in India," International Journal of Advanced Education and Research (IJAER) 5 (2020).

6 Utsav Raj, "Indian Education System in Fight against COVID-19 Pandemic.," Available at SSRN 3597340, 2020. 
Table 1: Level-wise Distribution of the Respondents

\begin{tabular}{|c|c|}
\hline Level of Education & Distribution \\
\hline Undergraduate Course & $150(50)$ \\
\hline Postgraduate Course & $150(50)$ \\
\hline
\end{tabular}

Notes : Figures in parentheses indicate percentages.

Source : Online survey.

Distribution of the respondents as per their genders is exhibited in table 2. Out of the total respondents, 52 percent $(n=156)$ were females and 48 percent $(n=144)$ were males.

Table 2: Gender-wise Distribution of the Respondents

\begin{tabular}{|c|c|}
\hline Gender & Distribution \\
\hline Female & $156(52)$ \\
\hline Male & $144(48)$ \\
\hline
\end{tabular}

Notes : Figures in parentheses indicate percentages.

Source : Online survey.

Distribution of the respondents as per their age groups is exhibited in table 3. Out of the total respondents, 55 percent $(n=165)$ were aged 21 and below, and 45 percent $(\mathrm{n}=135)$ were aged 21 and above.

Table 3: Age-wise Distribution of the Respondents

\begin{tabular}{|c|c|}
\hline Age (in Years) & Distribution \\
\hline 21 and below & $165(55)$ \\
\hline 21 and above & $135(45)$ \\
\hline
\end{tabular}

Notes : Figures in parentheses indicate percentages.

Source : Online survey.

Distribution of the respondents as per their residence area-type is exhibited in table 4 . Out of the total respondents, 47 percent $(n=141)$ were the residents of rural areas, 21 percent $(n=63)$ were the residents of semi-urban (township) areas, and 32 percent $(n=96)$ were the residents of urban areas. 
Table 4: Distribution of the Respondents as per Residence Area-type

\begin{tabular}{|c|c|}
\hline Residence Area-type & Distribution \\
\hline Rural & $141(47)$ \\
\hline Semi-urban (Township) & $63(21)$ \\
\hline Urban & $96(32)$ \\
\hline
\end{tabular}

Notes : Figures in parentheses indicate percentages.

Source : Online survey.

Distribution of the respondents as per their monthly family income is exhibited in table 5. Out of the total respondents, 62 percent $(n=186)$ had monthly family income up to $\otimes 20,000,19$ percent $(n=57)$ had monthly family income between $\square 20,001$ and $\otimes 40,000,9$ percent ( $n=27)$ had monthly family income between $\otimes 40,001$ and $\otimes 60,000,4$ percent $(n=12)$ had monthly family income between $\otimes 60,001$ and $\otimes 80,000$, and 6 percent $(n=18)$ had monthly family income up to $₫ 80,001$ and above.

Table 5: Distribution of the Respondents as per Monthly Family Income

\begin{tabular}{|c|c|}
\hline Monthly Family Income (₹) & Distribution \\
\hline Up to 20000 & $186(62)$ \\
\hline 20001 to 40000 & $57(19)$ \\
\hline 40001 to 60000 & $27(9)$ \\
\hline 60001 to 80000 & $12(4)$ \\
\hline 80001 and Above & $18(6)$ \\
\hline
\end{tabular}

Notes : Figures in parentheses indicate percentages.

Source : Online survey.

Distribution of the respondents as per discipline of studies is exhibited in table 6. Out of the total respondents, 58 percent $(n=174)$ were pursuing courses in Arts/Humanities/Social Sciences, 29 percent $(n=87)$ were pursuing courses in Commerce, 9 percent $(\mathrm{n}=27)$ were pursuing courses in Sciences, and 4 percent $(\mathrm{n}=12)$ were pursuing Professional Courses.

Table 6: Distribution of the Respondents as per Discipline of Studies

\begin{tabular}{|c|c|}
\hline Discipline of Studies & Distribution \\
\hline Arts/Humanities/Social Sciences & $174(58)$ \\
\hline Commerce & $87(29)$ \\
\hline
\end{tabular}




\begin{tabular}{|c|c|}
\hline Discipline of Studies & Distribution \\
\hline Sciences & $27(9)$ \\
\hline Professional Courses & $12(4)$ \\
\hline
\end{tabular}

Notes : Figures in parentheses indicate percentages.

Source : Online survey.

\section{Learning Status of the Respondents during Nationwide Lockdown}

Distribution of the respondents as per mode of learning during nationwide lockdown is exhibited in table 7. Out of the total respondents, 48 percent $(n=144)$ relied wholly on online mode of learning, none relied wholly on offline mode of learning, and 52 percent $(\mathrm{n}=156)$ relied on both online and offline modes of learning.

Table 7: Mode of Learning during Nationwide Lockdown

\begin{tabular}{|c|c|}
\hline Mode of Learning & Distribution \\
\hline Online only & $144(48)$ \\
\hline Offline only & -- \\
\hline Both Online and Offline & $156(52)$ \\
\hline
\end{tabular}

Notes : Figures in parentheses indicate percentages.

Source : Online survey.

Distribution of the respondents as per type of E-gadgets used for online learning during nationwide lockdown is exhibited in table 8. Out of the total respondents, 98 percent $(n=294)$ relied wholly on smart phones for online learning, 1 percent $(n=3)$ relied wholly on laptops/desktops for online learning, and 1 percent $(n=3)$ relied on both smart phones and laptops/desktops for online learning.

Table 8: Type of E-gadgets used for Online Learning during Nationwide Lockdown

\begin{tabular}{|c|c|}
\hline Type of E-gadgets & Distribution \\
\hline Smart Phone & $294(98)$ \\
\hline Laptop/Desktop & $3(1)$ \\
\hline Both Smart Phone and Laptop/Desktop & $3(1)$ \\
\hline
\end{tabular}

Notes : Figures in parentheses indicate percentages.

Source : Online survey. 
Distribution of the respondents as per platforms for online learning/sharing of study material during nationwide lockdown is exhibited in table 9. Out of the total respondents, 7 percent ( $\mathrm{n}=21)$ relied on Google Meet for online learning/ sharing of study material, 21 percent $(n=63)$ relied on Google Classroom for online learning/sharing of study material, 16 percent $(n=48)$ relied on Zoom for online learning/sharing of study material, 50 percent $(n=150)$ relied on Whatsapp for online learning/sharing of study material, and 6 percent $(n=18)$ relied on other platforms (such as emails, etc.) for online learning/sharing of study material.

Table 9: Platforms for Online Learning/Sharing of Study Material during Lockdown

\begin{tabular}{|c|c|}
\hline $\begin{array}{c}\text { Platforms for Online Learning/Sharing of } \\
\text { Study Material }\end{array}$ & Distribution \\
\hline Google Meet & $21(7)$ \\
\hline Google Classroom & $63(21)$ \\
\hline Zoom & $48(16)$ \\
\hline Whatsapp & $150(50)$ \\
\hline Others & $18(6)$ \\
\hline
\end{tabular}

Notes : Figures in parentheses indicate percentages.

Source : Online survey.

Distribution of the respondents as per percentage of syllabus completed during nationwide lockdown is exhibited in table 10 . Out of the total respondents, 38 percent $(\mathrm{n}=114)$ had completed less than 30 percent of their syllabus, 51 percent $(n=153)$ had completed their syllabus between 30 percent and 50 percent, and 11 percent $(n=33)$ had completed more than 50 percent of their syllabus.

Table 10: Percentage of Syllabus Completed during Nationwide Lockdown

\begin{tabular}{|c|c|}
\hline Percentage of Syllabus Completed & Distribution \\
\hline Less than $30 \%$ & $114(38)$ \\
\hline $30 \%$ to $50 \%$ & $153(51)$ \\
\hline More than $50 \%$ & $33(11)$ \\
\hline
\end{tabular}

Notes : Figures in parentheses indicate percentages.

Source : Online survey. 
Distribution of the respondents who accessed E-Pathshala during nationwide lockdown is exhibited in table 11 . Out of the total respondents, 66 percent $(n=198)$ had accessed to E-Pathshala, whereas 34 percent $(n=102)$ had not accessed E-Pathshala.

Table 11: Accessed E-Pathshala during Nationwide Lockdown

\begin{tabular}{|c|c|}
\hline Accessed E-Pathshala & Distribution \\
\hline Yes & $198(66)$ \\
\hline No & $102(34)$ \\
\hline
\end{tabular}

Notes : Figures in parentheses indicate percentages.

Source : Online survey.

Distribution of the respondents as per number of days a week online classes were held during nationwide lockdown is exhibited in table 12 . Out of the total respondents, 50 percent $(n=150)$ attended online classes up to 3 days a week, 38 percent $(\mathrm{n}=114)$ attended online classes between 4 days and 5 days a week, and 12 percent $(\mathrm{n}=36)$ attended online classes up to 7 days a week.

Table 12: Number of Days a Week Online Classes were held during Nationwide Lockdown

\begin{tabular}{|c|c|}
\hline Number of Days a Week Online Classes were held & Distribution \\
\hline Up to 3 Days & $150(50)$ \\
\hline 4 to 5 Days & $114(38)$ \\
\hline 7 Days a Week & $36(12)$ \\
\hline
\end{tabular}

Notes : Figures in parentheses indicate percentages.

Source : Online survey.

Distribution of the respondents as per number of hours a day they devoted to studies during nationwide lockdown is exhibited in table 13 . Out of the total respondents, 64 percent $(n=192)$ devoted up to 2 hours a day to studies, 32 percent $(\mathrm{n}=96)$ devoted between 2 hours and 5 hours a day to studies, and 4 percent $(n=12)$ devoted more than 5 hours a day to studies. 
Table 13: Number of Hours a Day they devoted to Studies during Nationwide Lockdown

\begin{tabular}{|l|l|}
\hline Number of Hours a Day devoted to Studies & Distribution \\
\hline Up to 2 Hours & $192(64)$ \\
\hline 2 to 5 Hours & $96(32)$ \\
\hline More than 5 Hours & $12(4)$ \\
\hline
\end{tabular}

Notes : Figures in parentheses indicate percentages.

Source : Online survey.

Distribution of the respondents as per availability of separate facility for studies at place of residence during nationwide lockdown is exhibited in table 14. Out of the total respondents, only 35 percent $(n=105)$ had availability of separate facility for studies at place of residence, whereas 65 percent $(n=195)$ did not have availability of separate facility for studies at place of residence.

Table 14: Availability of Separate Facility for Studies at Place of Residence during Nationwide Lockdown

\begin{tabular}{|c|c|}
\hline $\begin{array}{c}\text { Availability of Separate Facility for Studies at } \\
\text { Place of Residence }\end{array}$ & Distribution \\
\hline Yes & $105(35)$ \\
\hline No & $195(65)$ \\
\hline
\end{tabular}

Notes : Figures in parentheses indicate percentages.

Source : Online survey.

Distribution of the respondents as per their appearance in examination (online mode) during nationwide lockdown is exhibited in table 15. Out of the total respondents, only 22 percent $(n=66)$ appeared in examination (online mode), whereas 78 percent $(n=234)$ did not appear in any examination.

Table 15: Appearance in Examination (Online Mode) during Nationwide Lockdown

\begin{tabular}{|c|c|}
\hline Appearance in Examination (Online Mode) & Distribution \\
\hline Yes & $66(22)$ \\
\hline No & $234(78)$ \\
\hline
\end{tabular}

Notes : Figures in parentheses indicate percentages.

Source : Online survey. 
Distribution of the respondents as per platforms for their evaluation during nationwide lockdown is exhibited in table 16 . Out of the total respondents, 12 percent $(\mathrm{n}=36)$ were evaluated through Google Classroom, 5 percent $(\mathrm{n}=15)$ were evaluated through Email, 69 percent $(\mathrm{n}=207)$ were evaluated through Whatsapp, and 14 percent $(\mathrm{n}=42)$ were evaluated through other platforms.

Table 16: Platforms for their Evaluation of during Nationwide Lockdown

\begin{tabular}{|c|c|}
\hline Platforms for Evaluation & Distribution \\
\hline Google Classroom & $36(12)$ \\
\hline Email & $15(5)$ \\
\hline Whatsapp & $207(69)$ \\
\hline Others & $42(14)$ \\
\hline
\end{tabular}

Note : Figures in parentheses indicate percentages.

Source : Online survey.

Distribution of the respondents as per their opinion regarding re-opening of educational institutions in/or after September, 2020 is exhibited in table 17. Out of the total respondents, 35 percent $(n=105)$ opined that educational institutions should re-open in/or after September, 2020, 23 percent $(n=69)$ opined that educational institutions should not re-open in/or after September, 2020, and 42 percent $(n=126)$ did not have any opinion regarding re-opening of educational institutions in/or after September, 2020.

Table 17: Opinion regarding Re-opening of Educational Institutions in/or after September, 2020

\begin{tabular}{|c|c|}
\hline $\begin{array}{c}\text { Opinion regarding Re-opening of Educational } \\
\text { Institutions in/or after September, 2020 }\end{array}$ & Distribution \\
\hline Should Re-open & $105(35)$ \\
\hline Should Not Re-open & $69(23)$ \\
\hline Cannot Say & $126(42)$ \\
\hline
\end{tabular}

Note : Figures in parentheses indicate percentages.

Source : Online survey. 
5. Impact of Nationwide Lockdown on the Respondents and their Families

Distribution of the respondents as per problems faced by them during nationwide lockdown is exhibited in table 18. During nationwide lockdown, 68 percent $(n=204)$ of the respondents had to face financial problems, 8 percent $(n=24)$ of the respondents had to face food-related problems, 29 percent $(n=87)$ of the respondents had to face emotional/psychological problems, 19 percent $(n=57)$ of the respondents had to face physical health-related problems, and 6 percent $(n=18)$ of the respondents had to face other problems (such as reaching home, poor internet connectivity, etc.)

Table 18: Distribution of the Respondents as per Problems Faced by them during Lockdown

\begin{tabular}{|c|c|}
\hline Problems Faced & Distribution \\
\hline Financial & $204(68)$ \\
\hline Food-related & $24(8)$ \\
\hline Emotional/Psychological & $87(29)$ \\
\hline Physical Health-related & $57(19)$ \\
\hline Other & $18(6)$ \\
\hline
\end{tabular}

Notes : Data depicted in the table reflects multiples responses by the respondents. Figures in parentheses indicate percentages.

Source : Online survey.

Distribution of the respondents as per poor impact of nationwide lockdown on the financial positions of their families is exhibited in table 19. Out of the total respondents, 55 percent $(n=165)$ responded that nationwide lockdown had left a poor impact on the financial positions of their families and 45 percent $(n=135)$ responded that nationwide lockdown had not left a poor impact on the financial positions of their families. 
Table 19: Distribution of the Respondents as per Poor Impact of Nationwide Lockdown on the Financial Positions of their Families

\begin{tabular}{|c|c|}
\hline $\begin{array}{c}\text { Poor Impact of Nationwide Lockdown on the } \\
\text { Financial Positions of the Respondents' Families }\end{array}$ & Distribution \\
\hline Yes & $165(55)$ \\
\hline No & $135(45)$ \\
\hline
\end{tabular}

Note: Figures in parentheses indicate percentages.

Source: Online survey.

Distribution of the respondents as per their opinions regarding continuation of their education after nationwide lockdown is exhibited in table 20. Out of the total respondents, 64 percent $(n=192)$ responded that they will continue their education after nationwide lockdown is over and 36 percent $(n=108)$ responded that they will not continue their education after nationwide lockdown is over, due to the fact that the financial positions of their families had been hard-hit by nationwide lockdown situation.

Table 20: Distribution of the Respondents as per their Opinions regarding Continuation of their Education after Nationwide Lockdown

\begin{tabular}{|c|c|}
\hline Continuation of Education & Distribution \\
\hline Will Continue & $192(64)$ \\
\hline Will not Continue & $108(36)$ \\
\hline
\end{tabular}

Notes : $\quad$ Figures in parentheses indicate percentages.

Source : $\quad$ Online survey.

\section{Conclusion}

Due to 'COVID-19 pandemic' induced nationwide lockdown; the educational institution pan-India resorted to online/virtual mode of teachinglearning. However, with this new normal came many challenges. A substantial proportion of the students in India did not have access to modern e-gadgets and/or internet services to make the most of virtual/online mode of education. A portion of literature suggested that the preparedness of the education sector of India with respect to switching from offline mode of education to online mode seem to be a constraint. The present study found that all the respondents had access to e-gadgets and/or internet services in order to attend virtual/ online classes. However, most of the respondents ( $n=191,89$ percent) could 
only complete half of their syllabi in nationwide lockdown. It was observed that most of the respondents attended online classes 5 day a week, but most of the respondents ( $n=192,64$ percent) could devote only up to 2 hours a day to their studies. It could be due to the fact that 65 percent $(n=195)$ of the respondents did not have a separate facility for studies at their places of residence during nationwide lockdown. In order to continue their education in a normal fashion, a substantial proportion (35 percent) of the respondents said that educational institutions should re-open in or after September, 2020. The present study also found that most of the respondents ( $n=204,86$ percent) faced financial problems due to nationwide lockdown and a substantial proportion ( $n=144,48$ percent) of the respondents either faced physical health problems or emotional/psychological problems during nationwide lockdown. It may be concluded that nationwide lockdown has posed various challenges in the educational processes in general and the students in particular. For most of the students, this nationwide lockdown has affected the teaching-learning up to a great extent. It is, therefore, for the concerned authorities to make provisions for better infrastructural facilities in order to switch to the new normal of online/virtual mode of education. It is only then that the students, who are the prime stakeholders, may be able to participate in online/virtual teaching-learning processes.

\section{References}

Alvi, Muzna, and Manavi Gupta. "Learning in Times of Lockdown: How Covid-19 Is Affecting Education and Food Security in India." Food Security 12, no. 4 (2020): 793-96. https://doi.org/10.1007/s12571-020-01065-4.

Jena, Pravat Kumar. "Impact of Covid-19 on Higher Education in India." International Journal of Advanced Education and Research (IJAER) 5 (2020).

Prakash, Ravi, Tara Beattie, Prakash Javalkar, Parinita Bhattacharjee, Satyanarayana Ramanaik, Raghavendra Thalinja, Srikanta Murthy, Calum Davey, James Blanchard, and Charlotte Watts. "Correlates of School Dropout and Absenteeism among Adolescent Girls from Marginalized Community in North Karnataka, South India." Journal of Adolescence 61 (2017): 64-76.

Raj, Utsav. "Indian Education System in Fight against COVID-19 Pandemic." Available at SSRN 3597340, 2020.

UNESCO. School closures caused by Coronavirus (2020). Retrieved August 3, 2020, from https://en.unesco.org/covid19/educationresponse. 
